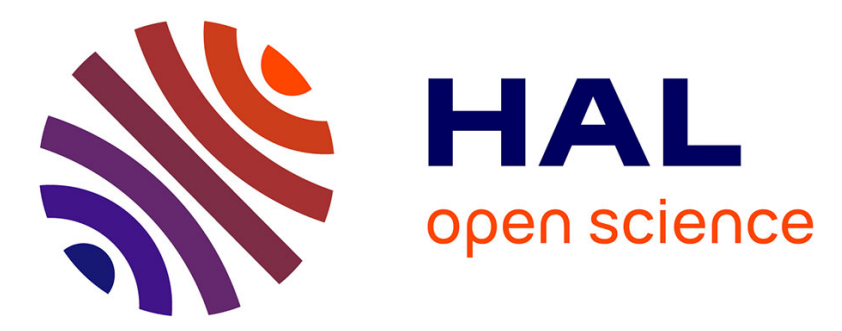

\title{
Deciphering Competitive Routes for Nickel-Based Nanoparticle Electrodeposition by an Operando Optical Monitoring
}

Louis Godeffroy, Paolo Ciocci, Anaclet Nsabimana, Mathias Miranda Vieira, Jean-marc Noël, Catherine Combellas, Jean-françois Lemineur, Frédéric Kanoufi

\section{To cite this version:}

Louis Godeffroy, Paolo Ciocci, Anaclet Nsabimana, Mathias Miranda Vieira, Jean-marc Noël, et al.. Deciphering Competitive Routes for Nickel-Based Nanoparticle Electrodeposition by an Operando Optical Monitoring. Angewandte Chemie International Edition, In press, 10.1002/anie.202106420 . hal-03287771

\section{HAL Id: hal-03287771 \\ https://hal.science/hal-03287771}

Submitted on 15 Jul 2021

HAL is a multi-disciplinary open access archive for the deposit and dissemination of scientific research documents, whether they are published or not. The documents may come from teaching and research institutions in France or abroad, or from public or private research centers.
L'archive ouverte pluridisciplinaire $\mathbf{H A L}$, est destinée au dépôt et à la diffusion de documents scientifiques de niveau recherche, publiés ou non, émanant des établissements d'enseignement et de recherche français ou étrangers, des laboratoires publics ou privés. 


\title{
Deciphering competitive routes for Ni-based nanoparticle electrodeposition by an operando optical monitoring
}

\author{
Louis Godeffroy, ${ }^{[a,+]}$ Paolo Ciocci, ${ }^{[a,+]}$ Anaclet Nsabimana,${ }^{[a,+]}$ Mathias Miranda Vieira, ${ }^{[a]}$ Jean-Marc \\ Noël, ${ }^{\left[{ }^{[a]}\right.}$ Catherine Combellas, ${ }^{[a]}$ Jean-François Lemineur, ${ }^{[a]}$ and Frédéric Kanoufi; ${ }^{[a]}$
}

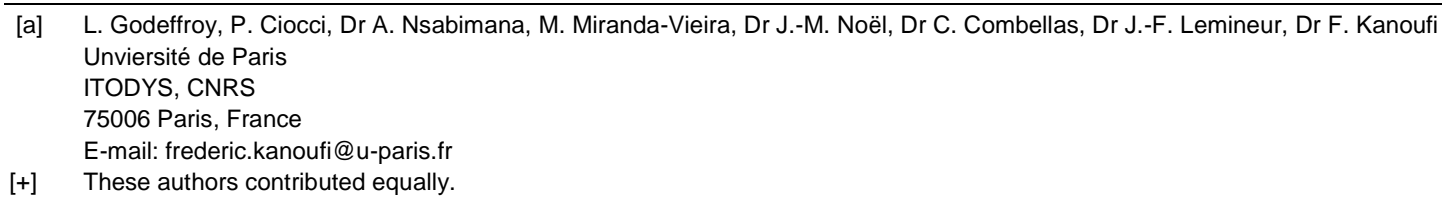

Supporting information, $\mathrm{SI}$, for this article is given via a link at the end of the document.

\begin{abstract}
Electrodeposition of earth-abundant iron group metals such as nickel is difficult to characterize by simple electrochemical analyses since the reduction of their metal salts often competes with inhibiting reactions. This makes the mechanistic interpretation sometimes contradictory, preventing unambiguous predictions about the nature and structure of the electrodeposited material. Herein, the complexity of $\mathrm{Ni}$ nanoparticles (NPs) electrodeposition on indium tin oxide (ITO) is unravelled operando and at a single entity NP level by optical microscopy correlated to ex situ SEM imaging. Our correlative approach allows differentiating the dynamics of formation of two different NP populations, metallic $\mathrm{Ni}$ and $\mathrm{Ni}(\mathrm{OH})_{2}$ with a $<25 \mathrm{~nm}$ limit of detection, their formation being ruled by the competition between $\mathrm{Ni}^{2+}$ and water reduction. At the single NP level this results in a self-terminated growth, an information which is most often hidden in ensemble averaged measurements.
\end{abstract}

The electrodeposition of metal-based nanostructures is paramount in various applications (next-generation transistors, or preparation of active electrodes). ${ }^{[1,2]}$ This is because the control of the electrode current or potential enables to predict the nature of the electrodeposits (composition, size, etc...). However, such prediction is more complex for earth-abundant iron group elements whose electrochemical reduction competes with inhibiting reactions such as water reduction. This is the case of nickel, $\mathrm{Ni}$, whose nanoparticles, NPs, in their metal or hydroxide form, afford promising electroactivity in energy conversion and storage systems. ${ }^{[3,4]}$ They are indeed good electrocatalysts for water splitting or oxygen reduction,,$^{[5,6]}$ and can even outperform platinum in borohydride fuel cells. ${ }^{[7]}$

Typically, the electrodeposition of $\mathrm{Ni}$-based materials yields a variety of electrochemical responses, depending on the electrolyte composition $(\mathrm{pH}$, buffer strength,...) and electrode (nature and preparation). Owing to its competition with water reduction, the signature of $\mathrm{Ni}^{2+}$ reduction may be absent from the electrochemical curve. ${ }^{[8-12]}$ Such competition produces either $\mathrm{Ni}$ or Ni-hydroxides, and the diversity of electrochemical responses makes the composition and electroactivity of the deposited material quite challenging to anticipate. ${ }^{[12]}$

To apprehend the contributions of such competing chemical pathways, a complementary in situ signature is needed..$^{[2,13-17]}$ E.g. coupling electrochemistry to high resolution label-free optical microscopy ${ }^{[15-17]}$ has proved to be effective to monitor metal deposition at single NPs with high temporal resolution and sensitivity, ${ }^{[18-21]}$ as well as to differentiate metallic NPs from other nanoobjects (e.g. dielectric NPs, ${ }^{[22-25]}$ gas nanobubbles $\left.{ }^{[26,27]}\right)$.
Herein the cathodic nucleation and growth of individual $\mathrm{Ni}$-based NPs on ITO, used as optical sensor and electrode, was scrutinized by interference reflection microscopy, IRM.

The experimental configuration is depicted in Fig. 1 (experimental details in supporting information, SI, section SI1). To capture the reported diversity in electrochemical signatures, we leverage the capability of scanning electrochemical cell microscopy, SECCM, ${ }^{[28]}$ to screen, electrochemically, at high throughput multiple areas of an electrode. Coupling SECCM to a correlated optical microscopy monitoring, ${ }^{[29,30]}$ grants a complementary screening of the behavior of these different areas, here through the super-localization identification of many individual NPs. This is performed by confining a droplet of a 1 to $5 \mathrm{mM} \mathrm{NiCl}_{2}+0.1 \mathrm{M} \mathrm{KCl}$ electrolyte on the ITO with the tip end of a micropipette, and imaging this microelectrochemical cell during linear sweep voltammetry (LSV), in reflection mode, by IRM. The optical signal, $\mathrm{I}_{\text {opt }}$, collected by the camera accounts for the interference between the light reflected by the ITO|droplet interface and the light backscattered by potential NPs (details in section SI2), enabling their operando individual optical visualization inside the microelectrochemical cell.

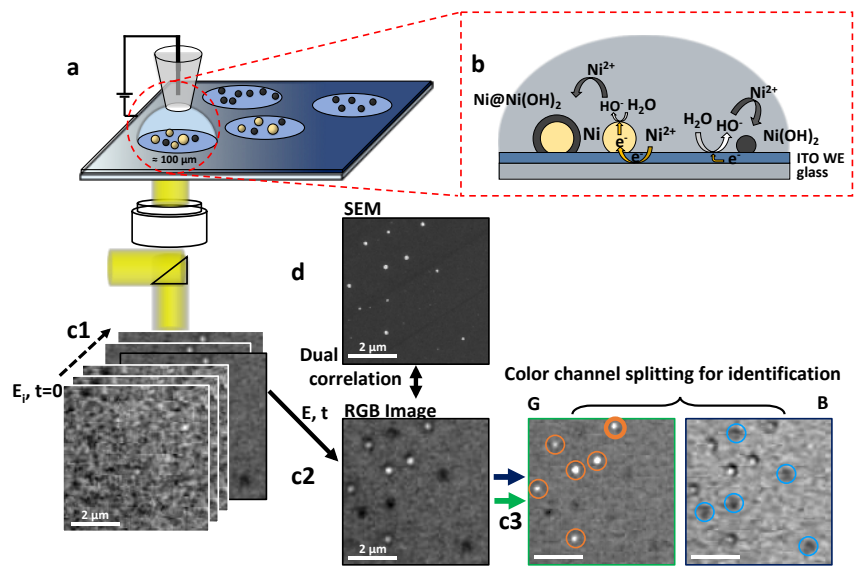

Figure 1. Experimental set-up (a) used for probing in individual microelectrochemical cells (dashed circle) the variability in Ni electrodeposition mechanisms (b) by operando optical monitoring (c1) and identical-location ex situ SEM (d). Scheme of the differentiation of NPs populations by splitting the color-channels (c3) of each raw RGB-image (c2) extracted from movies (c1) recorded over a $55 \times 39 \mu^{2}$ region of each droplet submitted to a LSV.

Owing to their contrasted refractive index, the presumed $\mathrm{Ni}$ and $\mathrm{Ni}(\mathrm{OH})_{2} \mathrm{NPs}$ should be distinguished by the IRM image analysis depicted in Fig.1c1-c3. Briefly, each recorded RGB image of the 
ITO is split along its three color-channels, respectively red, $R$, green, G, and blue, B (Fig.1c3). The less sensitive G channel detects the most scattering NPs as bright-contrasted features. Then, this population is subtracted from the more sensitive $B$ image, highlighting a new population of NPs detected as darkcontrasted features.

Fig. 2a1 and b1 show the two representative LSVs obtained for the reduction of a $1 \mathrm{mM} \mathrm{Ni}^{2+}$ from microdroplets deposited on different areas of the ITO, along with, in Fig. 2a2 and b2, the ensemble-averaged $\mathrm{I}_{\mathrm{opt}}$ variations for the two populations of optical features detected in their images (respectively Fig. 1c2 and Fig. SI3, extracted from videos S1 and S2). These experiments differ, respectively, from the presence or absence of a sharp reduction peak at $-1.45 \mathrm{~V}$, and the formation of either the two populations of bright- and dark-contrasted features or of only one population of dark-contrasted features. This difference of behavior is most likely due to the surface heterogeneities of the ITO surface that affect its electroactivity. ${ }^{[30]}$
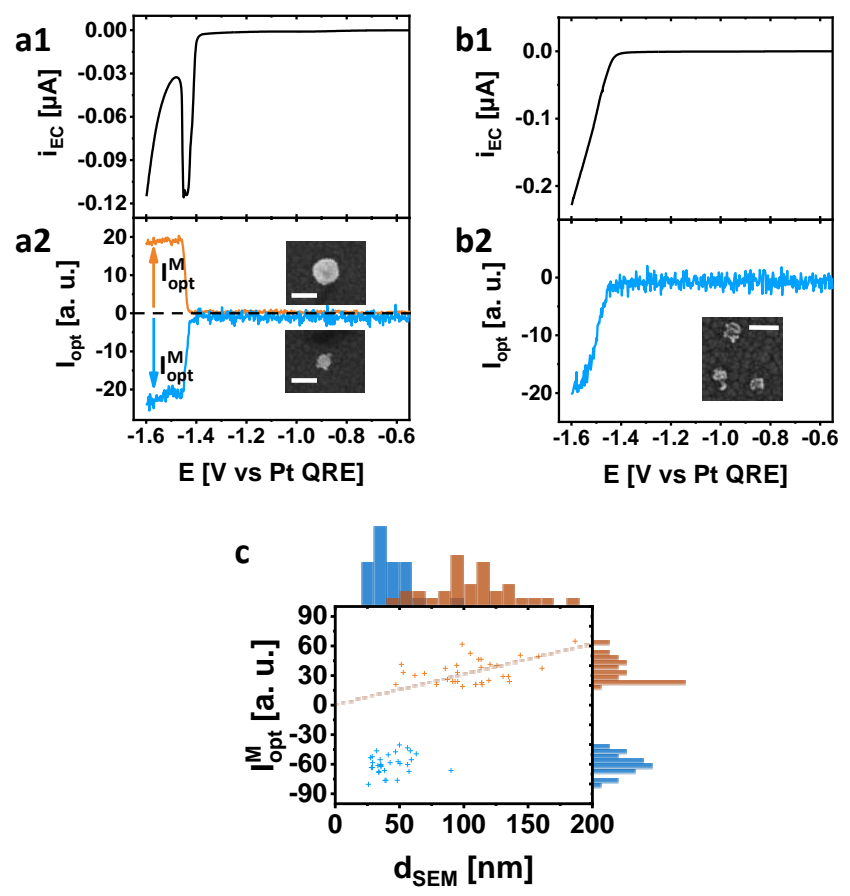

Figure 2. Examples of (a1, b1) LSVs of $1 \mathrm{mM} \mathrm{NiCl}_{2}+0.1 \mathrm{M} \mathrm{KCl}$ (scan rate: $50 \mathrm{mV} / \mathrm{s}$, vs a Pt quasi-reference electrode, QRE) and (a2, b2) ensembleaveraged optical intensity transients of the two different NPs populations (orange: bright-contrasted NPs, N=170 in (a2); light blue: dark-contrasted NPs, $\mathrm{N}=31$ in (a2) and 430 in (b2)). c) Identical location IRM-SEM: $\mathrm{I}_{\mathrm{opt}}^{\mathrm{M}}$, defined in (a2), vs size distribution for bright-contrasted (a) and dark-contrasted NPs (b); dashed line provides a linear regression $\left(\mathrm{I}_{\mathrm{opt}}^{\mathrm{M}}=\alpha \mathrm{d}_{\mathrm{SEM}}\right)$ for the brightcontrasted NPs. Scale bars: $100 \mathrm{~nm}$.

According to Moffat et al., ${ }^{[9,10]}$ the reduction peak in Fig. 2a1 ( $\approx 70 \%$ incidence from $20 \mathrm{LSVs}$ ), is related to $\mathrm{Ni}^{2+}$ reduction and deposition of a Ni film. However it is also concomitant to water reduction resulting in the precipitation of a $\mathrm{Ni}(\mathrm{OH})_{2}$ layer, which is a better catalyst than bare $\mathrm{Ni}^{[31,32]}$ for water reduction, until it completely blocks further charge transfer. The sharp current decay then supports an overall self-terminating deposition encountered in $\mathrm{Ni}$ and other metal electrodepositions. ${ }^{[10,33]}$ If the electrodeposition of a Ni film was confirmed when it was conducted in a $\mathrm{pH} \approx 6$ phosphate buffer (Fig. SI4), in the absence of $\mathrm{pH}$ buffer, the optical images (Fig. 1c2) suggest the formation of NPs. The ensemble-average $\mathrm{I}_{\mathrm{opt}}$ transient in Fig. 2a2 for each NPs population, respectively bright- and dark-contrasted, suggest that, in average, they evolve, until an optimum value of $\mathrm{I}_{\mathrm{opt}}^{\mathrm{M}}$ is reached, in a very narrow potential range confirming a fast-terminated growth correlated to the electrochemical peak, in line with a self-terminated growth mechanism.

Identical-location SEM imaging of the ITO electrode was performed at the end of the LSV (Fig. 1d). Unfortunately, the dimmer bright-contrasted NPs and many more dark-contrasted ones were lost or moved during the surface rinsing process. The bright-contrasted NPs are spherical (Fig. 2a2, top; additional images in section SI5) with a $110 \pm 50 \mathrm{~nm}$ size distribution (Fig. 2c). Their size roughly increases with the final value of their optical intensity, $\mathrm{I}_{\mathrm{opt}}^{\mathrm{M}}\left(\mathrm{r}^{2}=0.88\right.$, see section SI6), providing a $\approx 20 \mathrm{~nm}$ l.o.d. From both their regular spherical shape and optical simulations (section SI2), these bright-contrasted NPs are mostly composed of metallic Ni. According to Moffat, Ni should be covered by a $\mathrm{Ni}(\mathrm{OH})_{2}$ passivating layer. If this cannot be ascertained during the fast NP growth step ( $I_{\text {opt }}$ rise), a slight $I_{\text {opt }}$ decrease is observed after this growth step, attributed to $\mathrm{Ni}(\mathrm{OH})_{2}$ layer formation (section SI2, Figures SI2-2 and SI2-3).

The dark-contrasted NPS that could be co-localized by SEM after the LSVs resembling either to Fig $2 \mathrm{a} 1$ or to Fig. $2 \mathrm{~b} 1$, present smaller diameters $(40 \pm 15 \mathrm{~nm})$ than their brightcontrasted counterparts and have a more fractal shape (Fig. 2a2, bottom and Fig. 2b2; additional images in section SI5) similar to those obtained by cathodic electrosynthesis of $\mathrm{Ni}(\mathrm{OH})_{2} \mathrm{NPs} .{ }^{[1,34]}$ The absence of the $\mathrm{Ni}^{2+}$ reduction signature in the second type of LSV (Fig. 2b1) and the concomitant appearance of NPs with the water reduction wave (Fig. 2b2), suggest that they result from the precipitation of $\mathrm{Ni}(\mathrm{OH})_{2}$. Despite the lack of size- $\mathrm{I}_{\mathrm{opt}}^{\mathrm{M}}$ correlation (Fig. 2c) the IRM I.o.d. for $\mathrm{Ni}(\mathrm{OH})_{2} \mathrm{NPS}$ is again $<25 \mathrm{~nm}$.

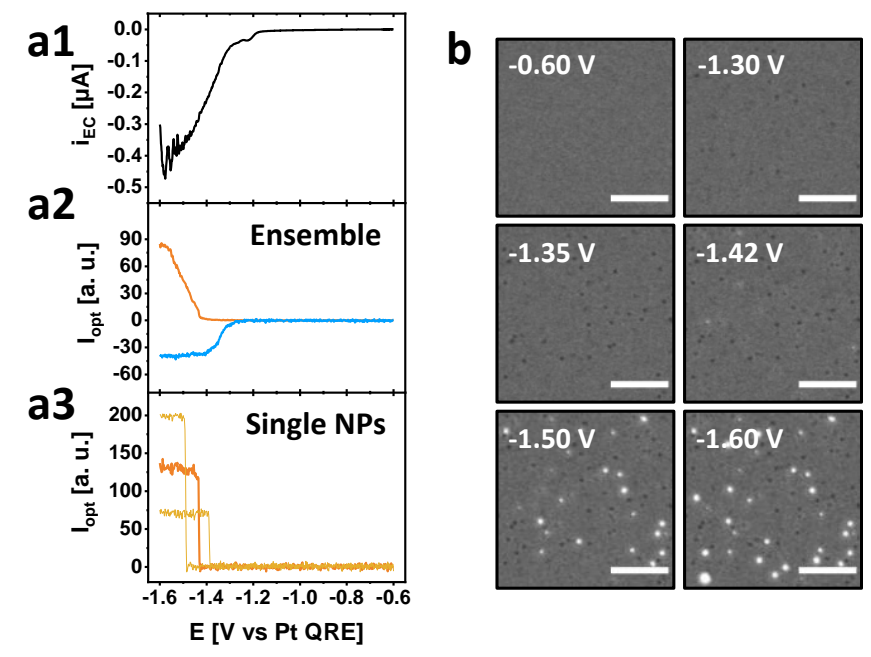

Figure 3. (a1) LSV at $50 \mathrm{mV} / \mathrm{s}$ of $5 \mathrm{mM} \mathrm{NiCl}_{2}+0.1 \mathrm{M} \mathrm{KCl}$, (a2) ensemble averaged optical intensity of both NPs populations (orange: bright-contrasted NPs, $N=354$; blue: dark-contrasted NPs, $N=427$ ), (a3) single NP optical transients of the median, first and third quartile of the Ni NP population. (b) Optical images during LSV (scale bars: $5 \mu \mathrm{m})$.

When the $\mathrm{Ni}^{2+}$ concentration was increased to $5 \mathrm{mM}$, the same variability in electrochemical responses was observed: showing either the $\mathrm{Ni}^{2+}$ reduction peak ( $37 \%$ occurrence of $54 \mathrm{LSVs}$ ), or 
only water reduction. An example of the latter case is presented in Fig. 3a. The optical images (Fig. 3b extracted from video S3) show the appearance of dark-contrasted $\mathrm{Ni}(\mathrm{OH})_{2} \mathrm{NPs}$ shortly after the onset of water reduction, like for the analogous LSV at $1 \mathrm{mM}$ in Fig. 2b1. However, bright-contrasted Ni NPs also appear at more negative potentials. Moreover, on the contrary to what was observed at $1 \mathrm{mM} \mathrm{Ni}^{2+}$, a gradual increase of $\mathrm{I}_{\mathrm{opt}}$ of the bright-contrasted Ni NPs is mainly observed (histogram in Figure $\mathrm{SI} 2-3)$. It is possible that the earlier water reduction and $\mathrm{Ni}(\mathrm{OH})_{2}$ NPs nucleation/growth lowers the local $\mathrm{pH}$. This could limit the formation of a $\mathrm{Ni}(\mathrm{OH})_{2}$ shell around the Ni NPs whose growth is not completely stopped.

Unlike in Fig. 2, even if water reduction is easier than $\mathrm{Ni}^{2+}$ reduction on this particular area, metallic Ni NPs are still able to nucleate without showing the $\mathrm{Ni}^{2+}$ reduction signature. This agrees with Penner et al. ${ }^{[8]}$ who demonstrated, by ex situ SEM, the indirect electrodeposition of pure Ni NPs on carbon electrodes even though water reduction was predominant. The same indirect Ni NP growth is demonstrated here with a wider diversity of phenomena observed thanks to the in situ complementary optical monitoring. It further allows discussing the change from direct to indirect Ni NPs growth. This is first evidenced from the difference in the ensemble-averaged $\mathrm{I}_{\mathrm{opt}}$ transients (Fig. 2a2 vs Fig. 3a2): the fast limited growth at $1 \mathrm{mM}$ becomes more gradual at $5 \mathrm{mM}$. Interestingly, at the single NP level, the $\mathrm{I}_{\mathrm{opt}}$ transients (Fig. 3a3) still present a sharp intensity rise, suggesting, again, the self-terminating growth of individual NPs. As pointed out for galvanic replacement at single $\mathrm{Ag}$ NPs, ${ }^{[17,19]}$ such individual behavior is totally obscured in the ensemble response, which then reflects the difference in the onset of appearance (nucleation) of each NP.

The latter nucleation was evaluated from the onset potential of individual NPs presented, along with their $\mathrm{I}_{\mathrm{opt}}^{\mathrm{M}}$ value, i.e. equivalently their final size, in Fig. 4 for both $\mathrm{Ni}^{2+}$ concentrations.
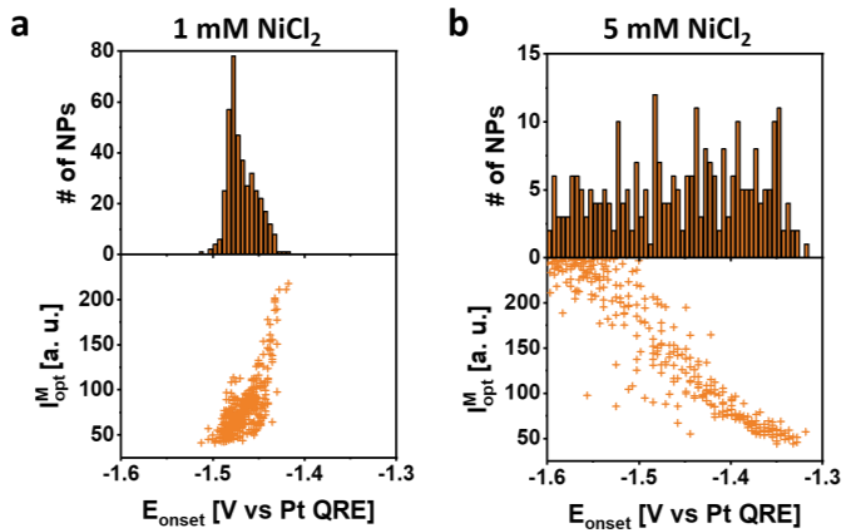

Figure 4. Onset potential distribution of Ni NPs and corresponding maximum optical intensity for $1 \mathrm{mM}(\mathrm{a}, \mathrm{N}=170)$ and $5 \mathrm{mM} \mathrm{Ni}^{2+}(\mathrm{b}, \mathrm{N}=334)$.

For $1 \mathrm{mM} \mathrm{Ni}^{2+}$ (Fig. 4a) the onset potential distribution presents a narrow peak, mimicking the sharp self-terminating $\mathrm{Ni}^{2+}$ reduction peak in LSV (Fig. 2a1). The sudden drop in nucleation events highlights the increased predominance of water reduction at potentials below $-1.5 \mathrm{~V}$. Moreover, the final NP size decreases as its onset potential becomes more negative: the earlier a NP nucleates, the larger it is at the end of the LSV, as time and reduction goes on. This situation is generally encountered in progressive electrochemical nucleation processes, e.g. NPs electrodeposition ${ }^{[20]}$ or gas nanobubbles generation. ${ }^{[27]}$ If it is also detected during the self-limited $\mathrm{Ni}$ growth, it is likely because the $\mathrm{pH}$ increases homogeneously over the NPs ensemble. Overall, water reduction limits $\mathrm{Ni}^{2+}$ reduction not only by limiting the growth of already nucleated Ni NPs, but also by limiting the formation of new nuclei.

Contrarily, for $5 \mathrm{mM} \mathrm{Ni}^{2+}$ (Fig. 4b) the nucleation frequency of new NPs is rather constant over the explored potential range. As mentioned above, the growth of individuals is still selfterminating (Fig. 3a3), the sum of all the sharp $(<0.3 \mathrm{~s})$ individual events at a constant frequency of nucleation event rationalizes the observed ensemble-averaged optical response of Fig. 3a2. Meanwhile, the final size of the NPs increases as their onset potential becomes more negative. This seemingly counterintuitive behavior shows the influence of the electrode potential on the competition between water and $\mathrm{Ni}^{2+}$ reduction. If the initial formation of $\mathrm{Ni}(\mathrm{OH})_{2} \mathrm{NPs}$ suggests water reduction dominates, the competition turns in favor of $\mathrm{Ni}^{2+}$ reduction at more negative potentials, the growth rate of $\mathrm{Ni}$ NPs increasing with overpotential. Moreover, during the first $100 \mathrm{mV}$ of the overall indirect deposition (Fig. 4b), NPs with a rather narrow size distribution $\left(\mathrm{I}_{\mathrm{opt}}^{\mathrm{M}}\right)$ are produced, at least much narrower than for their direct deposition (Fig. 4a), in agreement with Penner et al. ${ }^{[8]}$

In conclusion, high resolution optical microscopy coupled to electrochemistry and complemented with correlative SEM helps elucidating complex mechanisms associated to the electrodeposition of Ni-based NPs. The growth of metallic Ni and/or $\mathrm{Ni}(\mathrm{OH})_{2} \mathrm{NPs}$ are identified based on in situ optical differentiation with sub-25nm I.o.d. The preferential direct formation of both materials is usually rationalized based on the identification of either $\mathrm{Ni}^{2+}$ or water reduction signature in the electrochemical trace. In situ optical microscopy shows this is generally more complex. In particular, metallic Ni NPs can still nucleate and grow, indirectly, below the water reduction wave, although the $\mathrm{Ni}^{2+}$ reduction signature is invisible. Investigating these direct and indirect mechanisms at the single entity level highlights that individual NPs always experience a fast selfterminating growth, in agreement with the shape of the direct $\mathrm{Ni}^{2+}$ reduction signature. Contrarily, the indirect mechanism is characterized, from an ensemble-averaged examination, by a gradual growth. This difference reflects the change in nucleation dynamics, which is related to the competition between $\mathrm{Ni}^{2+}$ and water reduction. Overall, the proposed methodology allows probing, and in turn predicting in situ and in real time the size and surface density of Ni NPs. The methodology can be extended to the electrodeposition of the many NPs whose electrochemical signature lacks reproducibility or is difficult to identify. Particularly, the visualization of hydroxides should apply to electrocrystallization processes.

\section{Acknowledgements}

P.C. acknowledges funding from the European Union's Horizon 2020 research and innovation program under the Marie Skłodowska-Curie MSCA-ITN grant agreement no. 812398, through the single entity nanoelectrochemistry, SENTINEL, project. A.N. acknowledges support from the French scientific 
program MOPGA (FSPI-MOPGA-ACCLAIM). We acknowledge the ITODYS SEM facility, and the Université de Paris and CNRS for financial support.

Keywords: Electrodeposition • Optical microscopy • Single nanoparticle $\cdot$ Nickel $\cdot$ Nickel hydroxide

[1] R. M. Penner, J. Phys. Chem. B 2002, 106, 3339-3353.

[2] J. Ustarroz, Curr. Opin. Electrochem. 2020, 19, 144-152.

[3] C. Yuan, H. Bin Wu, Y. Xie, X. W. Lou, Angew. Chemie - Int. Ed. 2014, 53, 1488-1504.

[4] W. Li, B. Song, A. Manthiram, Chem. Soc. Rev. 2017, 46, 30063059.

[5] P. Du, R. Eisenberg, Energy Environ. Sci. 2012, 5, 6012-6021.

[6] Y. Li, X. Bao, D. Chen, Z. Wang, N. Dewangan, M. Li, Z. Xu, J. Wang, S. Kawi, Q. Zhong, ChemCatChem 2019, 11, 5913-5928.

[7] A. G. Oshchepkov, G. Braesch, S. Ould-Amara, G. Rostamikia, G. Maranzana, A. Bonnefont, V. Papaefthimiou, M. J. Janik, M. Chatenet, E. R. Savinova, ACS Catal. 2019, 9, 8520-8528.

[8] M. P. Zach, R. M. Penner, Adv. Mater. 2000, 12, 878-883.

[9] N. L. Ritzert, T. P. Moffat, J. Phys. Chem. C 2016, 120, 2747827489.

[10] R. Wang, U. Bertocci, H. Tan, L. A. Bendersky, T. P. Moffat, J. Phys. Chem. C 2016, 120, 16228-16237.

[11] J. Clausmeyer, J. Masa, E. Ventosa, D. Öhl, W. Schuhmann, Chem Commun. 2016, 52, 2408-2411.

[12] E. A. Mernissi Cherigui, K. Sentosun, P. Bouckenooge, H. Vanrompay, S. Bals, H. Terryn, J. Ustarroz, J. Phys. Chem. C 2017, 121, 9337-9347.

[13] J. Ustarroz, J. A. Hammons, T. Altantzis, A. Hubin, S. Bals, H Terryn, J. Am. Chem. Soc. 2013, 135, 11550-11561.

[14] H. E. M. Hussein, R. J. Maurer, H. Amari, J. J. P. Peters, L. Meng, R Beanland, M. E. Newton, J. V. Macpherson, ACS Nano 2018, 12, 7388-7396.

[15] W. Wang, Chem. Soc. Rev. 2018, 47, 2485-2508.

[16] B. S. Hoener, S. R. Kirchner, T. S. Heiderscheit, S. S. E. Collins, W.-S. Chang, S. Link, C. F. Landes, Chem 2018, 4, 1560-1585.

[17] A. J. Wilson, D. Devasia, P. K. Jain, Chem. Soc. Rev. 2020, 49,
$6087-6112$.

[17] A. J. Wilson, D. Devasia, P. K. Jain, Chem. Soc. Rev. 2020, 49,
6087-6112.

[18] C. M. Hill, S. Pan, J. Am. Chem. Soc. 2013, 135, 17250-17253.

[19] J. G. Smith, Q. Yang, P. K. Jain, Angew. Chemie Int. Ed. 2014, 53, 2867-2872.

[20] J.-F. Lemineur, J.-M. Noël, D. Ausserré, C. Combellas, F. Kanoufi, Angew. Chemie Int. Ed. 2018, 57, 11998-12002.

[21] S. Hu, J. Yi, Y.-J. Zhang, K.-Q. Lin, B.-J. Liu, L. Chen, C. Zhan, Z.-C. Lei, J.-J. Sun, C. Zong, J.-F. Li, B. Ren, Nat. Commun. 2020, 11 2518.

[22] R. W. Taylor, V. Sandoghdar, Nano Lett. 2019, 19, 4827-4835.

[23] C. Yurdakul, O. Avci, A. Matlock, A. J. Devaux, M. V. Quintero, E. Ozbay, R. A. Davey, J. H. Connor, W. C. Karl, L. Tian, M. S. Ünlü, ACS Nano 2020, 14, 2002-2013.

[24] J.-F. Lemineur, J.-M. Noël, A. Courty, D. Ausserré, C. Combellas, F. Kanoufi, J. Am. Chem. Soc. 2020, 142, 7937-7946.

[25] K. Namink, X. Meng, M. T. M. Koper, P. Kukura, S. Faez, Phys. Rev. Appl. 2020, 13, 044065.

[26] X. Shan, I. Díez-Pérez, L. Wang, P. Wiktor, Y. Gu, L. Zhang, W Wang, J. Lu, S. Wang, Q. Gong, J. Li, N. Tao, Nat. Nanotechnol. 2012, 7, 668-672.

[27] J.-F. Lemineur, P. Ciocci, J.-M. Noël, H. Ge, C. Combellas, F. Kanoufi, ACS Nano 2021, 15, 2643-2653.

[28] N. Ebejer, A. G. Güell, S. C. S. Lai, K. McKelvey, M. E. Snowden, P. R. Unwin, Annu. Rev. Anal. Chem. 2013, 6, 329-351.

[29] P. Saha, J. W. Hill, J. D. Walmsley, C. M. Hill, Anal. Chem. 2018, 90, 12832-12839.

[30] P. Ciocci, J. F. Lemineur, J. M. Noël, C. Combellas, F. Kanoufi, Electrochim. Acta 2021, 386, 138498.

[31] N. Danilovic, R. Subbaraman, D. Strmcnik, K. C. Chang, A. P. Paulikas, V. R. Stamenkovic, N. M. Markovic, Angew. Chemie - Int. Ed. 2012, 51, 12495-12498.

[32] M. Chhetri, S. Sultan, C. N. R. Rao, Proc. Natl. Acad. Sci. U. S. A 2017, 114, 8986-8990.

[33] Y. Liu, D. Gokcen, U. Bertocci, T. P. Moffat, Science (80-. ). 2012, 338, 1327-1330.

[34] F. Bagheri, S. Mosivand, Mater. Today Commun. 2021, 26, 101714. 
